\title{
A POLÍTICA EDUCACIONAL NOS GOVERNOS DO PT: CONTINUIDADES OU DESCONTINUIDADES EM RELAÇÃO AOS DO PSDB?
}

Nicholas Davies

\section{RESUMO}

Este texto pretende examinar semelhanças e diferenças das políticas educacionais dos governos federais do PT de 2003 a 2014 e do PSDB de 1995 a 2002 e conclui que são muito similares. Uma semelhança ocorre no ensino superior, com o incentivo à privatização por meio de programas como o FIES, o PROUNI e a conversão de dívidas de instituições privadas em bolsas, porém uma diferença é a política de cotas, adotada pelos governos do PT. Outro ponto em comum foi a virtual monopolização pelo governo federal de medidas que afetaram a educação nos Estados e prefeituras, que não foram sequer consultados. Outra semelhança foi a adoção de políticas de avaliação em larga escala com o objetivo declarado de contribuir para a melhoria de um tipo limitado de qualidade, cujo efeito tem sido responsabilizar quase exclusivamente as escolas e os professores e eximir os governantes pela qualidade do ensino. Uma diferença significativa foi a regulamentação do piso salarial nacional para profissionais do magistério.

Palavras-chave: Políticas educacionais federais; Educação básica; Ensino superior; Privatização.

\section{THE EDUCATIONAL POLICIES OF WORKERS' PARTY GOVERNMENT IN BRAZIL: CONTINUITIES OR DISCONTINUITIES COMPARED TO THOSE OF THE PSDB?}

\begin{abstract}
This text seeks to examine similarities and differences in the educational policies of the Workers' Party federal governments between 2003 and 2014 and those of the Brazilian Social-Democracy Party between 1995 and 2002 and concludes that they are quite similar. One similarity is in higher education, where privatization has been fostered by programmes such the FIES, the PROUNI and the conversion of private institutions' debts into student grants, yet a difference is the policy of quotas for low-income groups in higher education, adopted by PT governments. Another common feature was that the federal government virtually monopolized initiatives affecting education in the States and municipalities, which were not even consulted. A further similarity was the adoption of large-scale evaluation policies with the avowed aim of contributing to improve a limited type of quality, the effect of which has been to put the responsibility for quality almost exclusively on schools and teachers and exempt governments from the quality of education. A significant difference was the federal regulation of a national minimum salary for teaching personnel.
\end{abstract}

Keywords: Federal educational policies; Basic education; Higher education; Privatization. 


\section{Introdução}

Este trabalho pretende examinar, com base em pesquisa bibliográfica e documental (sobretudo legislação), semelhanças e diferenças das políticas educacionais dos governos federais do PT (Partido dos Trabalhadores), presididos por Luis Inácio Lula da Silva de 2003 a 2010 e Dilma Rousseff de 2011 a 2014, e do PSDB (Partido da Social Democracia Brasileira), presidido por Fernando Henrique Cardoso (FHC) de 1995 a 2002. Vale ressaltar que os governos, por mais diferentes que sejam ou aleguem ser, têm suas ações limitadas pela estrutura da sociedade e do Estado e, portanto, não podemos atribuir a eles toda a determinação/formulação/efeitos das políticas em geral e também das educacionais. Uma sociedade muito desigual, com extremos de riqueza e pobreza e, portanto, de exclusão social, como a brasileira, se reflete no caráter do Estado e em suas instituições, que tendem a reproduzir em maior ou menor grau tais extremos. As instituições permanentes do Estado (o legislativo, a burocracia em geral, o judiciário, a polícia, as forças armadas e outras) exercem um poder que afeta a desigualdade e escapam de modo geral ao controle dos governantes de plantão, que não conseguem mudar o núcleo essencial da estrutura do Estado, embora possam alterar vários mecanismos estatais por ações ou legislação.

Assim, um projeto de lei ou medida governamental pode ser alterada ou rejeitada total ou parcialmente pelo legislativo ou pelo judiciário (o Supremo Tribunal Federal, por exemplo) ou não cumprida pela burocracia permanente do Estado (os funcionários que não ocupam cargos de "confiança" no governo) sobre a qual o governo muitas vezes não tem poder. A Medida Provisória do FUNDEB (Fundo de Manutenção e Desenvolvimento da Educação Básica e de Valorização dos Profissionais da Educação), por exemplo, baixada pelo governo Lula no final de dezembro de 2006, sofreu alterações na Câmara dos Deputados no seu processo de conversão na Lei No. 11.494 (BRASIL, 2007), que distorceu o conteúdo da Medida Provisória e mesmo da Emenda Constitucional (EC) $\mathrm{N}^{\mathrm{o}}$ 53, que criou o FUNDEB, ao prever que os recursos do FUNDEB podem ser destinados a creches, pré-escolas e instituições de educação especial confessionais, filantrópicas e comunitárias sem fins "lucrativos" e conveniadas com o Poder Público, contradizendo a EC No 53, que reserva o FUNDEB apenas para a educação básica pública.

Outro exemplo é a política de cotas para ingresso nas instituições federais de ensino, que não incluiu as instituições de ensino militares federais, possivelmente porque este segmento da burocracia permanente do Estado não aceitava/aceita as cotas nas instituições que controla, sem nenhuma interferência da sociedade ou mesmo do MEC (o Ministério da Educação), em tese a instância governamental responsável pela educação em âmbito nacional/federal.

Por fim, as interpretações adotadas pelo Judiciário ou órgãos como os Tribunais de Contas podem mudar o sentido (mesmo o explícito) previsto na legislação ou em medidas governamentais.

Vale ressaltar que muitas políticas (fiscais/econômicas, por exemplo) formalmente não são educacionais porém se refletem nas políticas educacionais e, portanto, indiretamente podem ser consideradas como tal. Só examinei uma pequena seleção das políticas educacionais, que abrangem um leque muito variado: legislação, documentos governamentais, declarações de autoridades governamentais em geral (Ministro da Fazenda ou do Planejamento e Orçamento, por exemplo) ou da Educação, ações previstas ou não previstas em legislação ou documentos, omissões de determinações legais, descumprimento da legislação ou do previsto em documentos ou declarações governamentais. Os aspectos foram escolhidos em função do maior conhecimento que 
tenho deles e também da sua importância. Obviamente, muitos outros igualmente importantes poderiam ser abordados.

Vale frisar que vários aspectos são semelhantes e diferentes ao mesmo tempo e que a semelhança ou diferença nem sempre é total ou absoluta. Por exemplo, o incentivo às instituições privadas de ensino superior foi semelhante nos dois governos, porém apresentou algumas diferenças nos do PT. O Programa Universidade para "Todos" (PROUNI) é uma diferença por ser uma política de cotas mas semelhante por ser um incentivo ao ensino privado. O Fundo de Financiamento ao Estudante do Ensino Superior Privado (FIES), por sua vez, tinha características semelhantes nos dois governos, porém em 2007 se diferenciou (não totalmente) ao ser ampliado e contemplar estudantes de mestrado e doutorado em instituições privadas, ao passo que antes só contemplava alunos de graduação.

\section{As muitas semelhanças/continuidades e poucas diferenças/descontinuidades dos governos do PT e do PSDB}

Apesar de o PT e seus aliados terem enfatizado muito o caráter neoliberal das gestões do PSDB e que o governo do PT seria diferente, as suas políticas educacionais (e também outras) foram semelhantes às do PSDB em muitos aspectos. Neste sentido, representaram e representam uma continuidade (e às vezes aprofundamento), se bem que com algumas diferenças, ou descontinuidades. Indico e comento a seguir algumas delas.

Uma característica comum a ambos os governos é a centralização federal das decisões maiores da política educacional (e também da fiscal/econômica) que afetam a educação básica, a cargo de Estados, Distrito Federal (DF) e municípios, embora o PT, quando na oposição, tivesse um discurso de descentralização política, com mais poder de decisão para municípios e escolas, na suposição de que isso propiciaria a democratização da educação e da sociedade. Esta crença levou muitos a defenderem a municipalização (transferência de boa parte da responsabilidade educacional pelo ensino fundamental para municípios), supondo que em âmbito local o potencial democrático seria necessariamente maior.

Esta centralização revela a fragilidade do suposto pacto federativo, pois a consequência foi e é que Estados, DF, municípios e escolas se responsabilizam apenas pelas decisões menores ou a sua mera execução. São muitos os exemplos disso, praticados pelos dois governos e também pelos anteriores. Uma foi a iniciativa dos governos para aprovar (PSDB) ou prorrogar (PT) a vigência de emendas constitucionais (a mais recente foi conhecida como DRU - Desvinculação da Receita da União) que retiraram parte dos recursos vinculados à educação, um prejuízo de dezenas de bilhões de reais de 1994 a 2010 em âmbito federal, e de 1994 ao final de 1999, na esfera estadual, distrital e municipal.

É verdade que em 2009 a Emenda Constitucional (EC) No 59 (BRASIL, 2009) previu a extinção gradual dos efeitos deste prejuízo até o final de 2010. Desconheço as razões que levaram o PT a demorar tanto tempo para eliminar o fim dos efeitos da DRU na educação, sobretudo porque na oposição criticava (ou pelo menos alguns de seus setores) tal desvinculação. De qualquer modo, a EC $\mathrm{N}^{\circ} 59$ significou um avanço porém ao mesmo tempo maior responsabilidade educacional aos Estados, DF e municípios, ao ampliar o ensino obrigatório dos 4 aos 17 anos, abrangendo desde a pré-escola até o ensino médio, e não apenas dos 6 aos 14 anos, como atualmente, o que deveria ser feito progressivamente até 2016.

No entanto, até hoje a legislação não definiu a origem do maior volume de recursos para atender a esta maior responsabilidade e o projeto de lei (PL) do Plano Nacional de 
Educação (PNE) encaminhado pelo governo federal em dezembro de 2010 (BRASIL, 2010b) só previa 7\% do Produto Interno Bruto (PIB) para a educação (percentual quase idêntico ao PL de PNE anterior encaminhado pelo governo do PSDB em 1998), e isso ao final de 10 anos! É verdade que na tramitação do PL do governo a Câmara dos Deputados, por pressão de entidades da sociedade civil, foi levada a aumentar este percentual para $10 \%$ e reservá-lo à educação pública.

Embora a Lei do novo PNE, $N^{\circ} 13.005$, sancionada em junho de 2014, preveja, na meta 20 , que os $10 \%$ do PIB se destinem à educação pública, ela não é muito clara, pois o $\S 4^{0}$ do art. $5^{\circ}$ define que "O investimento público em educação a que se referem o inciso VI do art. 214 da Constituição Federal e a meta 20 do Anexo desta Lei engloba os recursos aplicados na forma do art. 212 da Constituição Federal e do art. 60 do Ato das Disposições Constitucionais Transitórias, bem como os recursos aplicados nos programas de expansão da educação profissional e superior, inclusive na forma de incentivo e isenção fiscal, as bolsas de estudos concedidas no Brasil e no exterior, os subsídios concedidos em programas de financiamento estudantil e o financiamento de creches, pré-escolas e de educação especial na forma do art. 213 da Constituição Federal" (grifo meu). Aparentemente, os percentuais se vinculam à educação pública, porém o Poder Público, no cálculo do investimento público em educação previsto no inciso VI do art. 214 da CF, poderá considerar os recursos públicos destinados a programas que beneficiam instituições privadas, como o FIES, creches, pré-escolas e de educação especial privadas sem fins lucrativos, isenção fiscal (PROUNI, por exemplo).

É verdade que a educação contará com mais recursos em virtude da Lei $\mathrm{N}^{\circ} 12.858$ (BRASIL, 2013), que prevê para a educação $75 \%$ dos royalties do petróleo descoberto em áreas novas, porém desconheço estudos demonstrando que bastarão para cobrir tal demanda maior. Além disso, a queda atual do preço do petróleo demonstra a fragilidade desta fonte de recursos.

Vale lembrar, no entanto, que esta lei não enfrenta o problema da desigualdade dos Estados e municípios no acesso aos royalties, o que significa que uns terão receita muito maior do que outros. Aliás, esta desigualdade atinge todas as esferas de governo (federal, estadual e municipal) e todos os tributos, não apenas os royalties, e não foi alterada (pelo menos significativamente) nem pelo PSDB nem pelo PT.

Entretanto, o avanço representado por esta EC $\mathrm{N}^{\circ}$ 59, aprovada só no final do segundo mandato do PT, foi e está sendo minado por medidas federais de desoneração tributária ou renúncia fiscal, que consiste em reduzir ou eliminar tributos com a justificativa de incentivar a economia como um todo ou um setor ou região específico, porém tem impacto negativo sobre receitas estaduais e municipais, constituídas em parte por impostos federais que integram os Fundos de Participação dos Estados (FPE) e Fundos de Participação dos Municípios (FPM), fragilizando a noção de pacto federativo.

Segundo o relatório do Tribunal de Contas da União (TCU) sobre as contas federais (BRASIL, TCU, 2013), o total de renúncias de receitas tributárias/previdenciárias/creditícias pelo governo federal teria atingido $\mathrm{R} \$ 216,5$ bilhões em 2012, muito superiores às despesas federais em educação ( $\mathrm{R} \$ 66,5$ bilhões) e saúde ( $\mathrm{R} \$$ 77,3 bilhões). De acordo com o Ministro José Jorge, relator do TCU sobre as contas, em 2012 a renúncia de $\mathrm{R} \$ 85$ bilhões da receita do Imposto de Renda (IR) e do Imposto sobre Produtos Industrializados (IPI) teria reduzido em R \$ 38 bilhões as transferências de impostos para Estados e municípios. Como pelo menos $25 \%$ deste montante é vinculado constitucionalmente à educação, isso significa um prejuízo de quase $\mathrm{R} \$ 10$ bilhões para a educação de Estados, do DF e municípios, valor quase idêntico à complementação federal para o FUNDEB (uma das prioridades declaradas do governo do PT) em 2012! Também a 
educação federal teria sido prejudicada por esta renúncia com a perda de no mínimo $\mathrm{R} \$ 10$ bilhões.

Outros exemplos desta centralização e, portanto, da fragilidade do suposto pacto federativo são o Fundo de Manutenção e Desenvolvimento do Ensino Fundamental e de Valorização do Magistério (FUNDEF) e o FUNDEB, criados pelo governo federal sem nenhuma consulta séria a Estados e municípios, embora estes sejam os maiores financiadores dos dois fundos e o governo federal tenha contribuído com muito pouco (FUNDEF) ou contribua com pouco (FUNDEB) para eles. Criado pelo governo de Fernando Henrique Cardoso (FHC) em 1996, implantado em 1998 e vigente até o final de 2006, vigorando, pois, durante alguns anos do governo de FHC (1998 a 2002) e 4 anos do governo Lula (2003 a 2006), o FUNDEF foi formado por 15\% de alguns impostos pertencentes a governos estaduais e municipais e repartido entre o governo estadual e os municipais de cada Estado de acordo com o número de matrículas no ensino fundamental, não trazendo recursos novos para a educação em âmbito estadual, pois era apenas uma redistribuição de uma parte dos impostos vinculados à educação. $O$ único recurso novo foi a complementação federal para os Estados em que o valor per capita não alcançasse o valor mínimo nacional, sendo irrisória durante toda a sua vigência, com menos de $1 \%$ (menos de R\$ 300 milhões) em 2006, quando a receita nacional foi superior a $\mathrm{R} \$ 35$ bilhões, formada quase totalmente pela contribuição de Estados e municípios. Além de irrisória, a complementação não cumpriu a Lei No 9.424 (BRASIL, 1996), que regulamentou o Fundef e estipula como ela deveria ser calculada. Assim, no FUNDEF os dois governos se assemelharam ao fazerem uma complementação federal irrisória e ilegal.

O FUNDEB, por sua vez, iniciativa do PT e implantado em 2007 para vigorar até o final de 2020, é semelhante ao FUNDEF, pois consiste apenas numa redistribuição de $20 \%$ de alguns impostos entre o governo estadual e as prefeituras de acordo com o número e o valor atribuído às matrículas municipais na educação infantil e no ensino fundamental e estaduais no ensino fundamental e no ensino médio. Outra semelhança é os dois governos priorizarem fundos para o financiamento da educação básica, com poucos recursos novos (a complementação federal) para o sistema educacional como um todo, se bem que no FUNDEB a complementação seja bem maior do que no FUNDEF.

No entanto, apresenta algumas diferenças em relação ao FUNDEF: o percentual (20\%) e o número de impostos é maior, é destinado à educação básica, e não apenas ao ensino fundamental, prevê valores diferentes para cada nível e modalidade de ensino e uma complementação federal bem maior. Uma diferença significativa, pelo menos para muitos municípios de alguns Estados sobretudo do Nordeste, é que a complementação (10\% da receita nacional a partir de 2010) aumenta bastante a receita para a educação, embora em termos nacionais não seja tão significativa quando se considera que o governo federal arrecada muito mais do que Estados e municípios.

Uma semelhança entre os dois fundos é que declaram pretender valorizar os professores no ensino fundamental (FUNDEF) ou os profissionais do magistério na educação básica (FUNDEB), ao vincular no mínimo $60 \%$ dos fundos para sua remuneração. Esta alegação é muito frágil, por várias razões. Uma é que, como os fundos consistem apenas numa redistribuição, dentro de cada Estado, de uma parte dos recursos vinculados à educação, alguns governos ganham com ele (recebem mais do que contribuem), enquanto que outros perdem (recebem menos do que contribuem), em função do número de matrículas no ensino fundamental (FUNDEF) ou na educação básica (FUNDEB). Obviamente, os governos que ganharam ou ganham têm condições objetivas de valorizar (no sentido de melhoria salarial) o magistério, o que não é garantia de que o farão, pois o controle social é inexistente ou muito frágil e os governadores e prefeitos de 
modo geral não são punidos se não aplicam a verba devida em educação. Já os governos que perderam ou perdem (e são milhares) não terão condições objetivas de melhorar os salários, pelo menos com base nos fundos. Até puderam ou podem fazê-lo com base nos recursos vinculados à educação e que não integraram o FUNDEF ou integram o FUNDEB. De qualquer modo, a lógica dos fundos não foi nem é garantia de valorização do magistério.

Apesar desta semelhança entre os dois fundos, o FUNDEB apresenta uma diferença significativa porque a EC No 53 (BRASIL, 2006), que o criou, prevê um piso salarial profissional nacional para o magistério da educação básica pública (não incluiu a privada), regulamentado pela Lei $\mathrm{N}^{\circ} 11.738$ (BRASIL, 2008), um avanço relativo, pois a Constituição Federal (CF) de 1988 já contemplava tal piso, só que não dizia que seria nacional e nunca havia sido regulamentado. Um aspecto interessante desta lei é estipular complementação da União se Estados, DF e municípios demonstrarem não ter condições de pagar o piso com base nos recursos constitucionalmente vinculados à educação. $\mathrm{O}$ problema é a viabilidade de o governo federal verificar se os demais governos aplicam tais recursos, pois os dados lançados pelos governos no sítio do Sistema de Informação sobre Orçamento Público em Educação (SIOPE), do Fundo Nacional de Desenvolvimento da Educação (FNDE), não são conferidos por nenhum órgão externo e independente e, portanto, não são necessariamente confiáveis, assim como a fiscalização pelos Tribunais de Contas tampouco é confiável, sem falar que o MEC não terá condições de fiscalizar in loco tal aplicação. Afinal, o Brasil tem 5.570 prefeituras, 26 governos estaduais e 1 do Distrito Federal.

Além disso, o piso de $\mathrm{R} \$ 950$ previsto pela lei para janeiro de 2008 era insignificante porque representaria em torno de 2 salários-mínimos e corresponderia a uma jornada de 40 horas, ou seja, em tese deveria ser suficiente para o profissional se manter e também a sua família e ele não teria tempo para outra atividade remunerada. O piso pode ser "generoso" quando se considera a miséria salarial de professores de prefeituras mais pobres ou que alegam pobreza, porém é um retrocesso em muitos Estados e municípios onde a remuneração superava $R \$ 950$ na época, sendo um nivelamento por baixo (a miséria como referência) e contradizendo a intenção declarada de valorização do magistério, pois, segundo a exposição de motivos do projeto de lei do governo, o piso corresponderia à "média mensal dos salários pagos aos profissionais da educação". Ora, se a intenção era valorizar o magistério, o piso não poderia tomar como referência os salários pagos (que eram muito baixos), mas sim os que deveriam/poderiam ser pagos, se não houvesse tantos desvios dos recursos da educação. Além disso, o nivelamento por baixo pode ter levado governos que pagavam mais do que o piso a não aumentarem a remuneração com a alegação de que já pagavam o piso.

Os dois fundos são mais uma comprovação da fragilidade do suposto pacto federativo (que é apenas formal), pois a sua lógica de repartição entre o governo estadual e as prefeituras de uma parte dos impostos vinculados à educação provocou/provoca diminuição da receita de governos estaduais e de milhares de prefeituras, embora seja verdade que milhares de prefeituras tenham ganho com o FUNDEF e ganhem com o FUNDEB.

Outra semelhança entre os governos dos dois partidos foi o descompromisso com o ensino fundamental (o ensino obrigatório), que era de 8 anos (7 aos 14) e passou recentemente a ser de 9 anos $(6$ aos 14) e a erradicação do analfabetismo, pois não cumpriram a CF de 1988 e a EC No 14 (BRASIL, 1996a), que os obrigavam (até 2006) a aplicar nele e na erradicação do analfabetismo um percentual mínimo dos impostos (o equivalente a 5,4\%). Esta erradicação só foi feita na legislação, pois a EC $\mathrm{N}^{\mathrm{o}} 53$, iniciativa 
do governo Lula em 2006, que alterou a EC Nº 14 e criou o FUNDEB, não prevê nada para tal finalidade. O resultado é que hoje o Brasil tem quase cerca de 15 milhões de analfabetos, segundo o Instituto Brasileiro de Geografia e Estatística (IBGE), sem falar nos analfabetos funcionais. É verdade que tal responsabilidade constitucional era/é também dos Estados, Distrito Federal e Municípios, pelo menos de 1988 a 1996 e que este descompromisso é histórico, sendo bem anterior aos governos do PSDB e do PT.

No entanto, na educação básica federal ocorreu uma diferença significativa, pelo menos em termos quantitativos. Segundo os Censos do Instituto Nacional de Estudos e Pesquisas Educacionais (INEP), em 1995 (primeiro ano do governo de FHC) as matrículas federais eram de 150.032, caindo para 113.732, em 2002 (último ano do governo). O número de escolas federais teria diminuído de 275, em 1995, para 202, em 2002. O quadro mudou bastante nos governos do PT, pois em 2012 as matrículas federais subiram para 276.436 e o número de escolas federais cresceu para 490. Apesar deste progresso, a participação federal nas matrículas da educação básica continua irrisória em termos nacionais, pois corresponde a cerca de $0,5 \%$ do total de matrículas estatais (conjunto de matrículas federais, estaduais, distritais, e municipais).

Outro exemplo de centralização e semelhança foram as políticas de avaliação em larga escala, que, embora com nomes diferentes - Sistema de Avaliação da Educação Básica (SAEB), Exame Nacional do Ensino Médio (ENEM), Exame Nacional de Cursos (o "Provão"), Exame Nacional de Desempenho Educacional (ENADE), Prova Brasil submeteu as escolas estaduais, distritais e municipais da educação básica e as instituições do ensino superior à lógica de avaliação do poder federal, com o objetivo declarado (o que não significa que seja o real) de avaliar um tipo muito limitado de qualidade de ensino e responsabilizar principalmente (na verdade, quase exclusivamente) escolas e professores pelos resultados e, por esta razão, as políticas dos dois governos enfatizaram muito a autonomia e gestão eficiente das escolas, para avaliar sua responsabilidade e desempenho e premiar este último, se satisfatório. Os efeitos concretos desta política têm sido tirar a responsabilidade dos governantes pelo que acontece nas escolas e no ensino.

O curioso nesta ênfase em avaliação e qualidade é que até hoje o governo federal não regulamentou o padrão de qualidade previsto na Constituição Federal e na LDB (BRASIL, 1996c), regulamentação esta que teria como consequência obrigar o governo federal a exercer função redistributiva e supletiva mediante assistência técnica e financeira aos Estados, Distrito Federal e Municípios, segundo a EC N 14 e o art. 75 da LDB, assim como não definiu o custo mínimo por aluno para assegurar ensino de qualidade, conforme prevê o art. 74 da LDB e motivo de muita insistência por parte das entidades que participaram da Conferência Nacional de Educação (BRASIL, CONAE, 2010a), em 2010, que desejavam fosse encampado pelo projeto de lei do Plano Nacional de Educação (BRASIL, 2010b) do governo federal, encaminhado ao Congresso Nacional em $2010 \mathrm{sem}$ esta reivindicação, além de muitas outras, como a de $10 \%$ do PIB. A não-regulamentação, portanto, desobriga legalmente o governo federal de qualquer ação redistributiva e supletiva. Quando ele redistribui recursos para Estados, municípios e escolas, por meio de programas como o Dinheiro Direto na Escola (PDDE), Transporte Escolar, da complementação para o FUNDEF ou o FUNDEB ou do Plano de Desenvolvimento da Educação (PDE), ele não se baseia num critério legal do padrão de qualidade (nunca regulamentado), mas sim em critérios específicos dos programas, fixados segundo os interesses do governo federal e que podem ser alterados a qualquer momento pela burocracia federal, sem depender de leis. Vale lembrar que a Lei do novo PNE, a $\mathrm{N}^{\circ}$ 13.005 (BRASIL, 2014b) só prevê a regulamentação do padrão de qualidade e do regime de colaboração no prazo de 2 anos a contar de 2014, o que significa que até ser aprovada a 
lei que regulamente isso (até 2016) o governo federal não é obrigado a complementar para garantir o padrão de qualidade em Estados e municípios.

Semelhanças e também diferenças podem ser constatadas nas políticas para o ensino superior. A comparação (ver tabela a seguir) entre as matrículas em 1994 (ano imediatamente anterior ao início do governo do PSDB - 1995), 2002 (último ano do governo do PSDB e o ano anterior à posse do governo do PT) e 2012 mostra que, em termos percentuais, as matrículas federais cresceram bem mais no governo do PT $(+104,5 \%)$ do que no do PSDB $(+46,2 \%)$ e as privadas aumentaram mais no governo do PSDB $(+150,2 \%)$ do que no do PT $(+111,7 \%)$. Entretanto, as matrículas privadas cresceram muito mais em termos absolutos nos governos do PT $(+2.712 .054)$ do que nos do PSDB (+1.457.674). Ou seja, a enorme expansão da rede privada, promovida e/ou permitida pelos governos do PSDB, foi não só continuada mas intensificada pelos governos petistas. O resultado foi que a participação privada, de $69,8 \%$ em 2002, elevou-se para $73 \%$ em 2012. Embora o número de matrículas federais tenha aumentado muito mais nos governos do PT (+ 555.779) do que nos do PSDB (+ 168.091), a participação federal no total nacional de matrículas, de $15,3 \%$ em 2002, elevou-se para apenas 15,5\% do total em 2012. Ou seja, a presença federal no ensino superior praticamente ficou estagnada em termos percentuais.

\section{Evolução das matrículas no ensino superior no Brasil de 1994 a 2012}

\begin{tabular}{|c|c|c|c|c|c|c|c|c|c|c|}
\hline & 1994 & $\begin{array}{|lr|}\% & \text { no } \\
\text { total } & \\
\end{array}$ & 2002 & 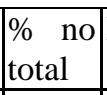 & \begin{tabular}{|l|} 
Evolução de \\
1994 a 2002 \\
\end{tabular} & $\begin{array}{l}\text { Evolu- } \\
\text { ção \% } \\
\end{array}$ & 2.012 & $\begin{array}{|ll|}\% & \text { no } \\
\text { total } & \\
\end{array}$ & \begin{tabular}{|l} 
Evolução de \\
2002 a 2012 \\
\end{tabular} & $\begin{array}{l}\text { Evolução } \\
\%\end{array}$ \\
\hline Federal & 363.543 & 21,9 & 531.634 & 15,3 & 168.091 & 46,2 & 1.087 .413 & 15,5 & 555.779 & 104,5 \\
\hline Estadual & 231.936 & 14,0 & 415.569 & 11,9 & 183.633 & 79,2 & 625.283 & 8,9 & 209.714 & 50,5 \\
\hline Municipal & 94.971 & 5,7 & 104.452 & 3,0 & 9.481 & 10,0 & 184.680 & 2,6 & 80.228 & 76,8 \\
\hline Privada & 970.584 & 58,4 & 2.428 .258 & 69,8 & 1.457 .674 & 150,2 & 5.140 .312 & 73,0 & 2.712 .054 & 111,7 \\
\hline Total & 1.661 .034 & & 3.479 .913 & & 1.818 .879 & 109,5 & 7.037 .688 & & 3.557 .775 & 102,2 \\
\hline
\end{tabular}

Fontes: Dados de 1994 - MEC. INEP. Evolução da educação superior - graduação: 1980-1998. Brasília: INEP, 1999. Disponível em: www.inep.gov.br. Acesso em: 15/03/2014. Dados de 2002 - MEC. INEP. Censo da educação superior 2002 (Tabela 5.1). Brasília: INEP, 2003. Disponível em: www.inep.gov.br. Acesso em: 15/03/2014. Dados de 2012 - MEC. INEP. Censo da educação superior 2012. Brasília: INEP, 2013. Disponível em: Disponível em: www.inep.gov.br. Acesso em: 1/11/2013.

Vale lembrar que as matrículas de 2012 incluem não apenas as presenciais mas também as de cursos a distância, bastante significativas, sobretudo as privadas, com 932.226. Quase 1/5 de todas as matrículas privadas (5.140.312) eram em cursos a distância, um número muito superior ao de matrículas federais (102.211), estaduais (64.778) e municipais (14.635). Isso significa que os cursos a distância são essencialmente privados. Estes números são infinitamente superiores aos registrados no Censo de 2002, quando o setor privado, embora predominante, era bem menor, com 32.132 matrículas. As matrículas federais, estaduais e municipais em cursos a distância eram, respectivamente, de 159, 9.200 e 61. As matrículas em cursos a distância em 2002 não foram significativas e, por isso, não foram incluídas no total da tabela acima. A enorme expansão privada na educação a distância no ensino superior é, pois, uma diferença significativa dos governos do PT em relação aos do PSDB.

Uma semelhança entre os governos e que explica, pelo menos em parte, a grande expansão das matrículas privadas é que eles adotaram o FIES, crédito educativo criado 
pelo governo de FHC em 1999 em substituição ao antigo crédito educativo (Creduc), implantado pela ditadura militar em 1976. Apesar de o programa ter sofrido várias alterações desde sua criação, sua característica básica é um empréstimo do governo federal (por meio de agentes como a Caixa Econômica Federal, substituído pelo FNDE) ao estudante para custear sua mensalidade em instituição privada e que deveria ser ressarcido em parte durante o curso pelo estudante e sobretudo após a sua conclusão. Inicialmente (1999), o programa se destinava apenas a alunos de graduação, ampliando-se depois para alunos de mestrado e doutorado (2007) e educação profissional e tecnológica (2011), desde que haja recursos e os cursos tenham avaliação positiva. $\mathrm{O}$ empréstimo é concedido na forma de certificados do Tesouro Nacional entregues às instituições privadas para quitação de dívidas (sobretudo previdenciárias) junto ao governo, contemplando prioritariamente bolsistas do PROUNI (explicado a seguir).

A importância destes dois programas federais (FIES e PROUNI) pode ser aferida pela Lei $N^{\circ} 12.956$ (BRASIL, 2014a), de fevereiro de 2014, sancionada pela presidente Dilma, abrindo crédito de R \$ 2,5 bilhões para o FIES, pelos créditos de mais de R\$5,4 bilhões para o FIES em 2013, segundo o FNDE (BRASIL, MEC, FNDE, 2014), e pelo fato de o PROUNI ter oferecido mais de 1,2 milhão de bolsas integrais e parciais de 2005 a 2013, segundo o Sisprouni (o Sistema do MEC para o PROUNI) de 6/11/2013, cujo número expressivo se explica pelo menos em parte porque o FIES prioriza os bolsistas parciais do PROUNI. Segundo notícia publicada na Rede Brasil Atual (SARTORATO, 2014), com base em dados divulgados pelo MEC, o PROUNI e o FIES responderiam por $30 \%$ das matrículas (1,6 milhão) em instituições privadas, tendo o orçamento anual do FIES no governo Dilma aumentado de $\mathrm{R} \$ 1,8$ bilhão para $\mathrm{R} \$ 7,5$ bilhões.

Um outro benefício para as instituições privadas de ensino foi previsto na Lei No. 12.688 (BRASIL, 2012a), que prevê a quitação de suas dívidas junto ao governo federal mediante uma série de condições e facultando até $90 \%$ das prestações mensais das dívidas serem convertidas em bolsas integrais.

Uma diferença significativa entre os dois governos foi que o do PT implementou política de cotas privilegiadas de acesso ao ensino superior privado e federal, com o discurso de que com isso estaria democratizando o acesso a ele. Foi instituída por duas leis, uma em 2005, outra em 2012. A de 2005, Lei No 11.096 (BRASIL, 2005), conhecida como o PROUNI, prevê um percentual de bolsas (basicamente $10 \%$ dos alunos pagantes) em instituições privadas de ensino superior (IES) para candidatos classificados como carentes em troca de isenções de impostos e contribuições destas IES, cuja adesão ao programa é voluntária. O principal e primeiro critério é o candidato ter feito todo o ensino médio em escola pública ou sido bolsista integral em escola privada e não ter diploma de curso superior. Outro critério, concomitante ao primeiro, é o candidato ter uma renda familiar mensal per capita de até 3 salários mínimos. Este critério se divide em dois: para os que têm uma renda familiar mensal de até 1 salário mínimo e meio, a bolsa é integral. Para os com renda entre 1 salário mínimo e meio e 3 salários mínimos, a bolsa é parcial (50\% ou $25 \%)$. Os candidatos, além de preencher um destes critérios, podem ser contemplados com um percentual das vagas se declaram ser portadores de deficiência ou indígenas, pardos ou pretos, percentual correspondente à proporção destes segmentos registrada no censo do IBGE. A única exceção para o preenchimento destas vagas é o professor da rede pública que queira fazer licenciatura, normal superior ou pedagogia, que não precisa atender a nenhum destes requisitos. O candidato seria selecionado também pelos resultados e pelo perfil socioeconômico registrados no Exame Nacional do Ensino Médio (ENEM) ou outros critérios a serem definidos pelo MEC e, na etapa final, pela IES, segundo seus próprios critérios. As isenções são variáveis em função das 3 classes de IES: 
(a) com fins lucrativos, (b) sem fins lucrativos que não sejam filantrópicas (beneficentes), e (c) filantrópicas.

Já a Lei de 2012, de No 12.711 (BRASIL, 2012b), previu cotas (no mínimo 50\% até 2016) e subcotas dos $50 \%$ das vagas por cursos e turno em instituições federais de ensino superior (IFES) para quem cursou integralmente o ensino médio em escolas públicas, e de ensino técnico de nível médio, para quem fez o ensino fundamental apenas em escolas públicas. Seriam preenchidas na proporção de 1/4 cada ano (ou seja, 12,5\% cada ano) a partir da promulgação da lei, ou seja, o percentual de $50 \%$ deverá ser cumprido integralmente até agosto de 2016. Os critérios das subcotas são: metade de todas as vagas são para aqueles com renda familiar mensal per capita igual ou inferior a 1,5 saláriomínimo (critério apenas econômico). Uma proporção da outra metade será destinada a candidatos que se declarem pretos, pardos ou indígenas (critério de autodeclaração de cor), correspondente no mínimo ao percentual de pretos, pardos e indígenas na população da unidade da Federação onde fica a instituição, segundo o censo mais recente do IBGE. Se num Estado 30\% se declaram negros, $40 \%$ se dizem pardos, e 1,99\% alegam ser indígenas, o total de $71,99 \%$ da metade das vagas serão reservadas a eles (desde que tenham feito o ensino médio em escola pública), restando, pois, $28,01 \%$ para os que não declararam ter esta cor. Se as vagas das subcotas não forem preenchidas segundo os critérios acima, serão destinadas a quem tenha cursado integralmente o ensino médio em escolas públicas. Os mesmos critérios são utilizados no caso das instituições federais de ensino técnico de nível médio, cujos candidatos deverão ter cursado integralmente o ensino fundamental em escolas públicas.

Esta política de cotas, ainda que defendida como mecanismo de democratização do acesso, apresenta muitas fragilidades, algumas indicadas a seguir. Uma é que, no caso do acesso às federais, só uma proporção muito pequena (bem menos de 10\%) dos concluintes do ensino médio público serão elegíveis, pois o número de vagas federais oferecidas em 2012 foi de 322.532 (Censo da Educação Superior de 2012), o que significa que o número de vagas seria em torno de $161 \mathrm{mil}$ hoje (com base no percentual de $50 \%$ a ser aplicado apenas em 2016), enquanto o número de concluintes (total do ensino médio regular, EJA presencial e EJA semipresencial público) foi de 1.924.753 em 2012. Ou seja, mais de 1,75 milhão de concluintes estariam excluídos deste acesso supostamente democrático às federais, podendo, no entanto, ser absorvidos pelas IES privadas, que ofereceram 4.043.096 vagas em 2012, o que é uma democratização muito peculiar, pois, segundo as avaliações feitas pelo próprio governo, as IES privadas de modo geral são mal classificadas na comparação com as estatais.

Outra fragilidade é que o governo federal reconhece, com a reserva de vagas, que a escola pública (na verdade, estatal) é pior e se limita a oferecer com as cotas um consolo a ela e seus alunos. A consequência é que nem ela nem seus alunos precisam melhorar pois pelo menos uma parte (ínfima, na verdade) deles já tem garantido acesso privilegiado ao ensino superior. Outra é privilegiar o critério da autodeclaração de cor da pele, quando o critério decisivo ou, pelo menos, muito mais importante, é renda familiar. Outro ponto fraco é que, no caso do PROUNI, a reserva de vagas para alunos de escolas estatais em IES privadas fortalece tais instituições, que, desta forma, diminuem as suas vagas ociosas e também a inadimplência (graças ao FIES) nelas.

Há também problemas como o da confiabilidade do critério da autodeclaração, da verificação da renda familiar per capita (muitos têm renda não declarada ou registrada), e também o fato de várias escolas estatais (ligadas a instituições estatais, por exemplo) serem frequentadas por alunos de bom poder aquisitivo, razoável capital cultural e serem consideradas de boa qualidade (segundo a definição tradicional de boa qualidade). Além 
disso, a exigência de cursar o ensino público pode ser contornada por quem frequenta o ensino público e depois paga um pré-vestibular privado ou mesmo faz paralelamente o público e o privado, o público para fins formais (o diploma), o diploma para o conteúdo necessário para o ENEM. Há ainda o problema da manutenção dos alunos, que podem ingressar mas não conseguir se manter nos cursos.

Por fim, a política de cotas transforma as instituições de ensino superior em bodes expiatórios dos problemas sociais e escolares, além de desrespeitar sua autonomia, sendo oferecido a elas apenas o consolo de poderem utilizar o ENEM para selecionar candidatos da política de cotas. $O$ curioso é que tal política não se aplica às instituições militares federais de ensino médio e superior, o que pode ser interpretado como o grande poder dos militares e como ainda se veem como um corpo à parte da sociedade e de suas regras e instituições, apesar do fim formal da ditadura militar em 1985, interpretação confirmada pela sua postura de não-colaboração com a Comissão da Verdade, que procurou investigar as torturas, assassinatos e atos de desrespeito aos direitos humanos cometidos pela ditadura militar de 1964 a 1985.

\section{Considerações finais}

Este breve texto pretendeu apontar algumas semelhanças/continuidades e diferenças/descontinuidades nas políticas educacionais dos governos do PT (2003-2014) e do PSDB (1995-2002). A conclusão principal é a de que muitas medidas dos dois governos são similares, apesar de o PT, quando na oposição, criticar medidas dos governos do PSDB como neoliberais e reclamar da "herança maldita" deixada pelo governo anterior. O exemplo mais óbvio é a privatização do ensino superior, que não só foi mantida, mas também aprofundada pelos governos do PT, por meio de programas como o FIES, o PROUNI e a conversão de dívidas de instituições privadas em bolsas. É verdade que tais programas e também a reserva de vagas a alunos de escolas públicas, com baixa renda e que se autodeclarem como negros, pardos e índios em instituições federais de ensino superior são apresentados e defendidos como mecanismos de "democratização" de acesso ao ensino superior. Porém, além do impacto eleitoral, têm servido também e sobretudo para reduzir a inadimplência e a capacidade ociosa das instituições privadas, cuja qualidade menor, atestada pelo próprio MEC, enfraquece bastante o discurso da democratização, pois parece ser uma educação pobre para pobre. Esta política de cotas representa uma mudança significativa do PT em relação aos governos do PSDB.

Outra semelhança foi a virtual monopolização pelo governo federal de medidas que afetaram e afetam a educação nos Estados e prefeituras, que não são sequer consultados. $\mathrm{O}$ FUNDEF e o FUNDEB, por exemplo, foram criados por iniciativa única do governo federal, que não os consultou, embora os entes subnacionais fossem e sejam os grandes financiadores dos fundos. Contraditoriamente, o governo federal contribuiu muito pouco para o FUNDEF e contribui relativamente pouco (10\% do total) para o FUNDEB. A fragilidade do suposto pacto federativo fica evidente também no caso de medidas como a desoneração tributária adotada pelo governo federal nos últimos anos sem qualquer consulta aos entes subnacionais, que resulta em redução de impostos para Estados e prefeituras e, portanto, para a educação. Uma diferença significativa foi a regulamentação do piso salarial nacional para profissionais do magistério, embora em valor irrisório e de difícil implementação e fiscalização pelo MEC e órgãos independentes.

Outra semelhança é a adoção de políticas de avaliação em larga escala com o objetivo declarado de contribuir para a melhoria de um tipo limitado de qualidade, cujo efeito tem sido responsabilizar quase exclusivamente as escolas e os professores e eximir 
os governantes pela qualidade do ensino. Contraditoriamente, apesar desta ênfase discursiva em qualidade, estes governos até hoje não regulamentaram o padrão de qualidade previsto na CF de 1988 e também na LDB, possivelmente porque isto exigiria do governo federal o exercício da ação supletiva e redistributiva em favor dos entes subnacionais para a garantia de tal padrão.

Em síntese, as políticas educacionais dos governos do PSDB e do PT foram muito mais semelhantes do que diferentes, apesar das críticas do PT às políticas neoliberais e à "herança maldita" deixada pelos governos de FHC.

\section{Referências}

BRASIL. Congresso Nacional. Constituição da República Federativa do Brasil. Brasília: Senado Federal, 1988. Disponível em <http://www.planalto.gov.br>. Acesso em: mar. 2014.

BRASIL. Decreto N ${ }^{\circ}$ 6.094, de 24 de abril de 2007. Dispõe sobre a implementação do Plano de Metas Compromisso Todos pela Educação, pela União Federal, em regime de colaboração com Municípios, Distrito Federal e Estados, e a participação das famílias e da comunidade, mediante programas e ações de assistência técnica e financeira, visando a mobilização social pela melhoria da qualidade da educação básica. Diário Oficial da União, Brasília, DF, 25 abr. 2007.

BRASIL. Emenda Constitucional No 14, de 12 de setembro de 1996. Modifica os arts. 34, 208, 211212 da CF e dá nova redação ao art. 60 do Ato das Disposições Constitucionais Transitórias. Diário Oficial da União, Brasília, DF, 13 set. 1996a. Disponível em: <http://www.planalto.gov.br/> Acesso em: 10 mar. 2014.

BRASIL. Emenda Constitucional N $\mathrm{N}^{\mathrm{o}}$ 53, de 19 de dezembro de 2006. Dá nova redação aos arts. $7^{\circ}, 23,30,206,208,211$ e 212 da Constituição Federal e ao art. 60 do Ato das Disposições Constitucionais Transitórias. Diário Oficial da União, Brasília, DF, 20 dez. 2006. Disponível em: <http://www.planalto.gov.br/> Acesso em: 10 mar. 2014.

BRASIL. Emenda Constitucional $N^{\circ} 59$, de 11 de novembro de 2009. Acrescenta $\S 3^{\circ}$ ao art. 76 do Ato das Disposições Constitucionais Transitórias para reduzir, anualmente, a partir do exercício de 2009, o percentual da Desvinculação das Receitas da União incidente sobre os recursos destinados à manutenção e desenvolvimento do ensino de que trata o art. 212 da Constituição Federal, dá nova redação aos incisos I e VII do art. 208, de forma a prever a obrigatoriedade do ensino de quatro a dezessete anos e ampliar a abrangência dos programas suplementares para todas as etapas da educação básica, e dá nova redação ao $\S$ $4^{\circ}$ do art. 211 e ao $\S 3^{\circ}$ do art. 212 e ao caput do art. 214, com a inserção neste dispositivo de inciso VI. Diário Oficial da União, 12 nov. 2009, Brasília, DF. Disponível em: <http://www.planalto.gov.br/> Acesso em: 10 mar. 2014.

BRASIL. Lei $\mathrm{N}^{\circ}$ 12.711, de 29 de agosto de 2012. Dispõe sobre o ingresso nas universidades federais e nas instituições federais de ensino técnico de nível médio e dá outras providências. Diário Oficial da União, Brasília, DF, 30 ago. 2012b. Disponível em: <http://www.planalto.gov.br/> Acesso em: 10 mar. 2014.

BRASIL. Lei $n^{\circ}$ 10.172, de 09 de janeiro de 2001. Aprova o Plano Nacional de Educação (PNE). Diário Oficial da União, Brasília, DF, 10 jan. 2001a. Disponível em: <http://www.planalto.gov.br/> Acesso em: 10 mar. 2001. 
BRASIL. Lei N $\mathrm{N}^{\mathrm{1}}$ 10.260, de 12 de julho de 2001. Dispõe sobre o Fundo de Financiamento ao Estudante do Ensino Superior e dá outras providências. Diário Oficial da União, Brasília, DF, 13 jul. 2001b. Disponível em: <http://www.planalto.gov.br/> Acesso em: 10 mar. 2014.

BRASIL. Lei N ${ }^{\circ} 11.096$, de 13 de janeiro de 2005. Institui o Programa Universidade para Todos - PROUNI, regula a atuação de entidades beneficentes de assistência social no ensino superior; altera a Lei $\mathrm{N}^{\circ} 10.891$, de 9 de julho de 2004, e dá outras providências. Diário Oficial da União, Brasília, DF, 14 jan. 2005. Disponível em: <http://www.planalto.gov.br/> Acesso em: 10 mar. 2014.

BRASIL. Lei No 11.494, de 20 de junho de 2007. Regulamenta o Fundo de Manutenção e Desenvolvimento da Educação Básica e de Valorização dos Profissionais da Educação FUNDEB, de que trata o art. 60 do Ato das Disposições Constitucionais Transitórias; altera a Lei $\mathrm{n}^{\mathrm{o}} 10.195$, de 14 de fevereiro de 2001; revoga dispositivos das Leis nos 9.424, de 24 de dezembro de 1996, 10.880, de 9 de junho de 2004, e 10.845, de 5 de março de 2004; e dá outras providências. Diário Oficial da União, Brasília, DF, 21 jun. 2007. Disponível em: <http://www.planalto.gov.br/> Acesso em: 10 mar. 2014.

BRASIL. Lei No 11.738, de 16 de julho de 2008. Regulamenta a alínea "e" do inciso III do caput do art. 60 do Ato das Disposições Constitucionais Transitórias, para instituir o piso salarial profissional nacional para os profissionais do magistério público da educação básica. Diário Oficial da União, Brasília, DF, 17 jul. 2008. Disponível em: <http://www.planalto.gov.br/> Acesso em: 10 mar. 2014.

BRASIL. Lei No 12.688, de 18 de julho de 2012. Institui o Programa de Estímulo à Reestruturação e ao Fortalecimento das Instituições de Ensino Superior (PROIES). Diário Oficial da União, edição extra, Brasília, 19 jul. 2012a. Disponível em: <http://www.planalto.gov.br/> Acesso em: 10 mar. 2014.

BRASIL. Lei $\mathrm{N}^{\circ} 12.858$, de 9 de setembro de 2013. Dispõe sobre a destinação para as áreas de educação e saúde de parcela da participação no resultado ou da compensação financeira pela exploração de petróleo e gás natural, com a finalidade de cumprimento da meta prevista no inciso VI do caput do art. 214 e no art. 196 da Constituição Federal; altera a Lei ${ }^{\circ} 7.990$, de 28 de dezembro de 1989; e dá outras providências. Diário Oficial da União, Brasília, DF, 10 set. 2013. Disponível em: <http://www.planalto.gov.br/> Acesso em: 10 mar. 2014.

BRASIL. Lei No 12.956, de 27 de fevereiro de 2014. Abre crédito extraordinário, em favor de Operações Oficiais de Crédito, no valor de $\mathrm{R} \$ 2.531 .486 .253,00$, para o fim que especifica. Diário Oficial da União, Brasília, DF, 28 fev. 2014a. Disponível em: <http://www.planalto.gov.br/> Acesso em: 10 mar. 2014.

BRASIL. Lei No 13.005, de 25 de junho de 2014. Aprova o Plano Nacional de Educação e dá outras providências. Diário Oficial da União, edição extra, Brasília, DF, 26 jun. 2014b.

BRASIL. Lei No 9.394, de 20 de dezembro de 1996. Estabelece as diretrizes e bases da educação nacional. Diário Oficial da União, Brasília, DF, 23 dez. 1996c. Disponível em: <http://www.planalto.gov.br/> Acesso em: 10 mar. 2014.

BRASIL. Lei No. 9.424, de 24 de dezembro de 1996. Dispõe sobre o Fundo de Manutenção e Desenvolvimento do Ensino Fundamental e de Valorização do Magistério, na forma prevista no art. $60, \S 7^{\circ}$, do Ato das Disposições Constitucionais Transitórias, e 
dá outras providências. Diário Oficial da União, Brasília, DF, 26 dez. 1996b. Disponível em: <http://www.planalto.gov.br/> Acesso em: 10 dez. 2010.

BRASIL. MEC. FNDE. Relatório de gestão: 2013. Brasília, DF, 2014. Disponível em www.fnde.gov.br. Acesso em: 10 mai. 2014.

BRASIL. MEC. Relatório do GT sobre o cálculo do valor mínimo do FUNDEF. Brasília, 2003. Disponível em <www.mec.gov.br>. Acesso em: set. 2003.

BRASIL. Presidência da República. MEC. Secretaria Executiva. [CONAE 2010]. Documento-Final. Brasília, 2010a. Disponível em: <http://www.mec.gov.br>. Acesso em: jul. 2010.

BRASIL. Presidência da República. Projeto de Lei No 8.035/10, de 20/12/2010. Aprova o Plano Nacional de Educação para o decênio 2011-2020 e dá outras providências. Brasília, 2010b. Disponível em: www.planalto.gov.br. Acesso em: 10 jan. 2011.

BRASIL. TCU (Tribunal de Contas da União). Relatório e parecer prévio sobre as contas do governo da República. Exercício de 2012. Item "Renúncia de receitas: benefícios tributários, financeiros e creditícios". Disponível em: www.tcu.gov.br. Acesso em: 20 abr. 2014.

CARVALHO, Cristina Helena Almeida de. O PROUNI no governo Lula e o jogo político em torno do acesso ao ensino superior. Educação e Sociedade, Campinas, v. 27, n.96, out. 2006.

CATANI, Afrânio Mendes \& HEY, Ana Paula \& GILIOLI, Renato de Sousa Porto. PROUNI: democratização do acesso às Instituições de Ensino Superior? Educar em Revista, Curitiba, n. 28, jul./dez. 2006.

FERREIRA, Suely. Reformas na educação superior: de FHC a Dilma Rousseff (19952011). Linhas Críticas, Brasília, DF, n. 36, p. 455-472, mai./ago. 2012. Acesso em: 20 mar. 2014.

OLIVEIRA, Dalila Andrade. As políticas educacionais no governo Lula: rupturas e permanências. Revista de Política e Administração da Educação, Porto Alegre, v. 25, n. 2, p. 197-209, mai./ago. 2009.

PEREIRA, Maria de Fátima Rodrigues; PEIXOTO, Elza Margarida de Mendonça. A distância: a escola Lula para a formação de professores. Revista Histedbr On-Line, Campinas, n. 40, p. 179-188, dez. 2010. Acesso em: 20 mar. 2014.

SARTORATO, Diego. Prouni e Fies já respondem por $30 \%$ das matrículas em universidades privadas. 14/3/2014. Disponível em www.redebrasilatual.com.br. Acesso em: 20 abr. 2014.

SAVIANI, Dermeval. PDE: Plano de Desenvolvimento da Educação: análise crítica da política do MEC. Campinas: Autores Associados, 2009.

WERLE, Flávia Obino Corrêa. A reinvenção da gestão dos sistemas de ensino: uma discussão do Plano de Desenvolvimento da Educação (2007). Revista Educação em Questão, Natal, v. 35, p. 98-119, maio/ago., 2009.

Recebido: maio-15 Aprovado: julho-15 